دراسة تحليلية لأثار الحروب على عمارة وعمران المدن العربية

3 ممدوح على يوسف الت

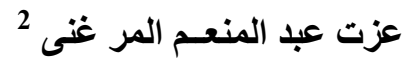

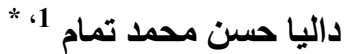

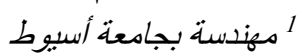

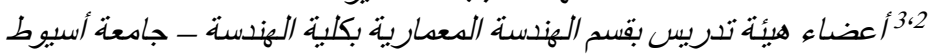

Received 14 January 2014; revised 26 January 2014; accepted 20 February 2014

الملخص

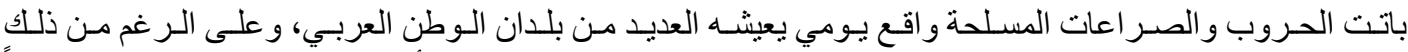

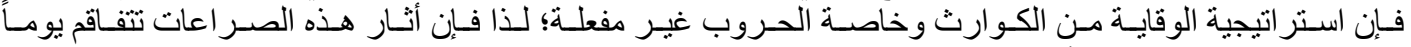

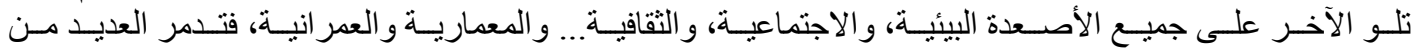

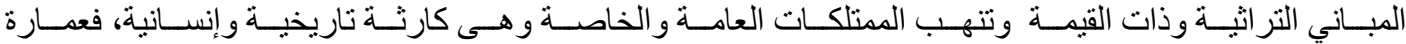
الحاضر هي تاريخ المستقبل.

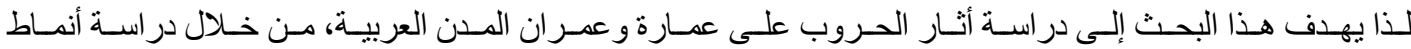

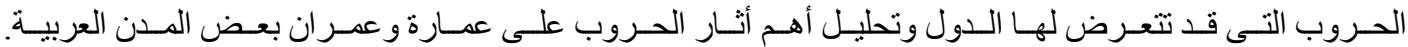

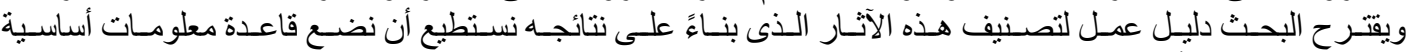

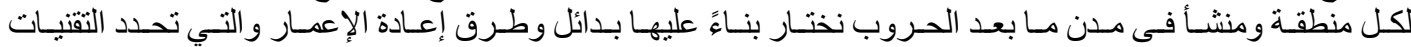

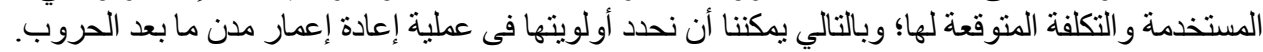

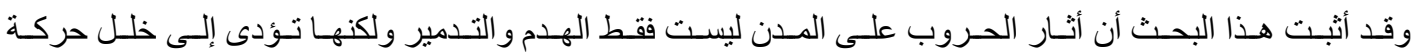

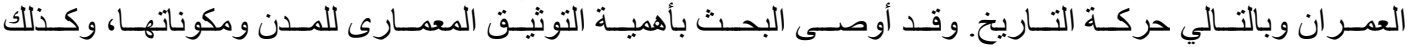

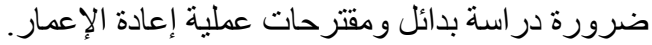

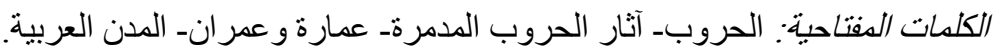

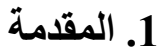

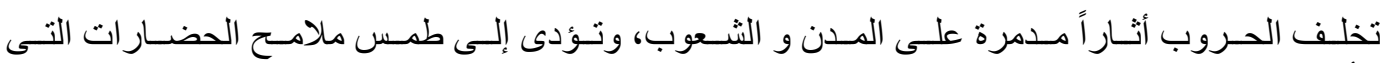

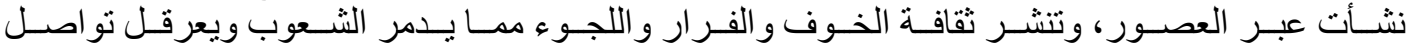

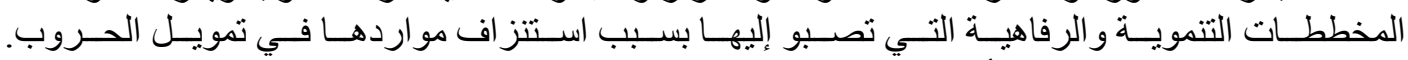

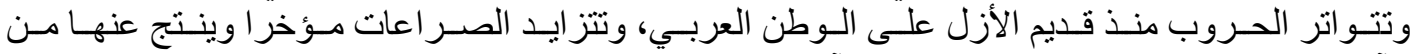

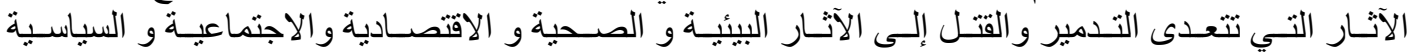

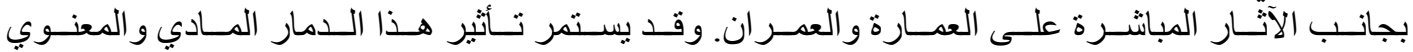
لأجيال لم تعاصر تللك الحروب.

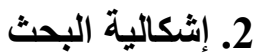

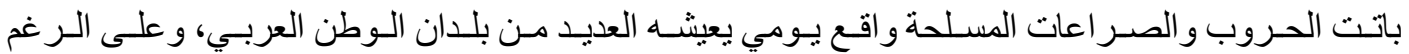

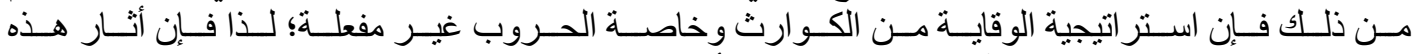

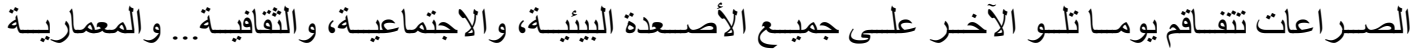

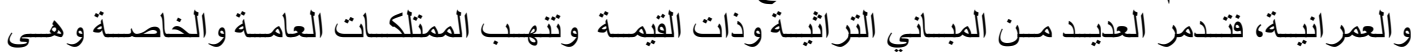

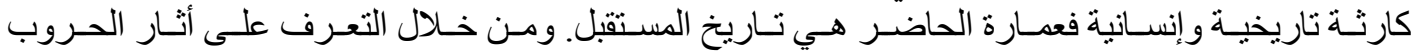

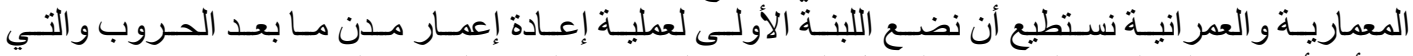

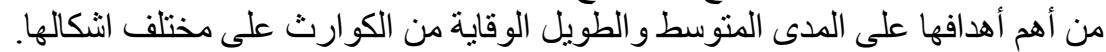

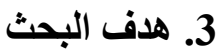

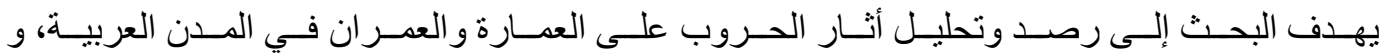

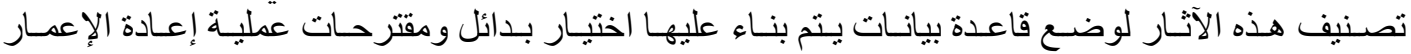
لمدن ما بعد الحروب. 
ويمكن تحقيق الهدف الأساسي فى البحث من خلال الدراسات التالية:

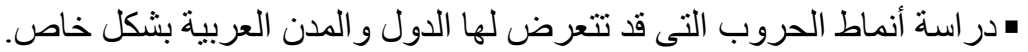

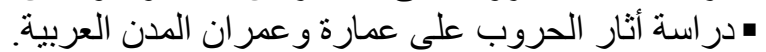
• تصنيف هذه الآثار لإعداد قاعدة بيانات يتم بناء عليها اختيار بدائل ومقترحات عملية إعادة الإعمار.

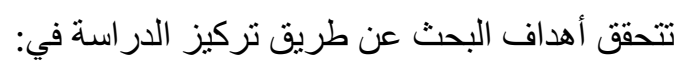

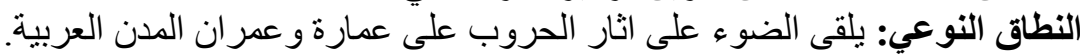

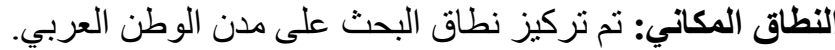

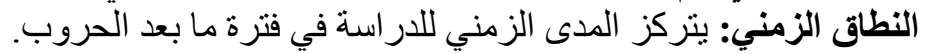

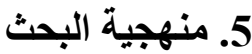

تعنمد منهجية البحث على المنهج الونة الوصفي التحليلي.

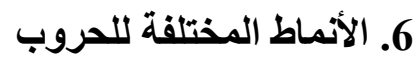

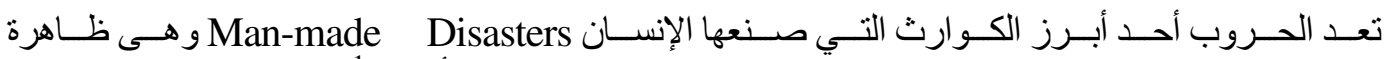

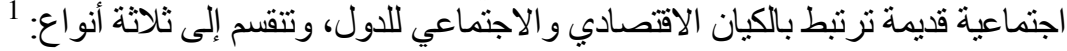

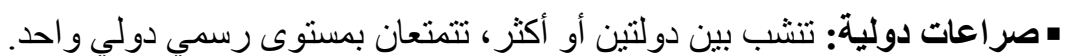

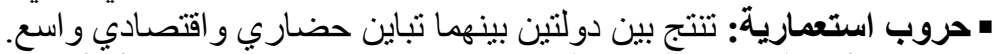

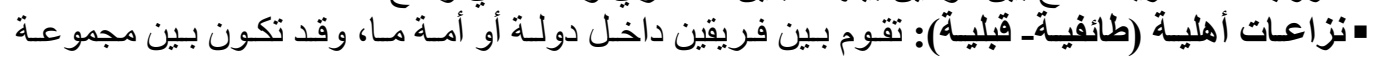
ثائرة أو متمردة وحكومة رسمية. وتصنف الحروب حسب أهدافها، طرق خوضها، أونها، مستو اها، مدتها وقو اها المنصار عة، فتقسم إلى:

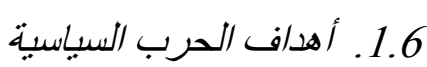

تقوم الحروب السياسية تبعاً لأهدافها التي تسعى لتحقيقها أو الوصول إليها، ومن أهم صور هذه الحروب:

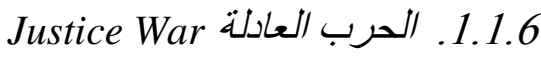

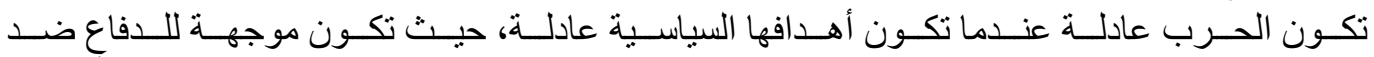

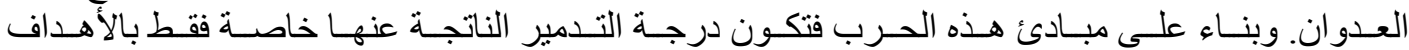

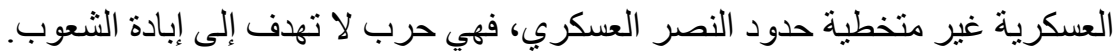

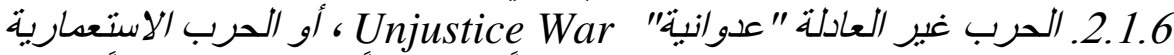

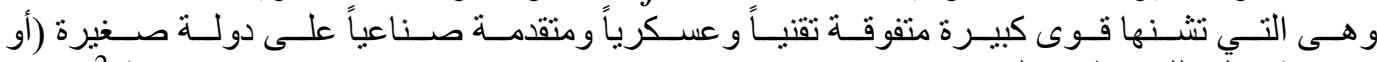

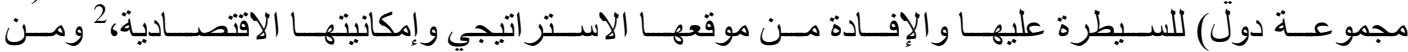
أثكالها:

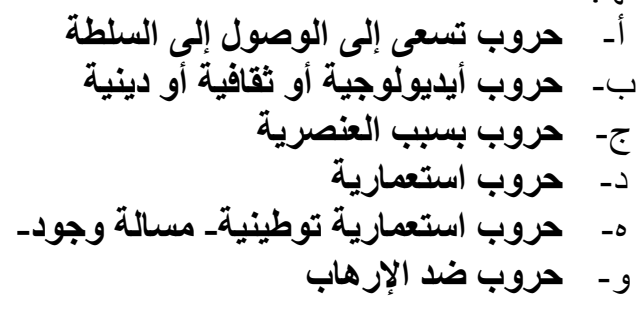

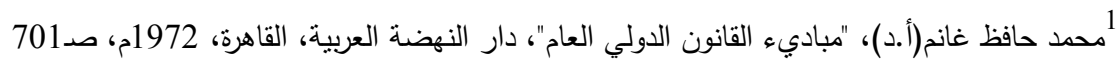

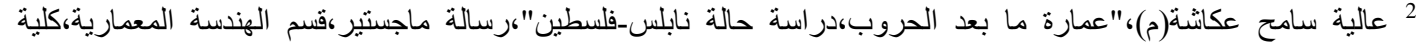




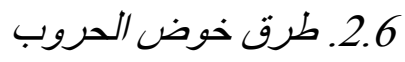

وتعنى هذه الحروب بنوع التكتيك و الثقتية المستخدمة فى الصر اع، وتنقسم إلى:

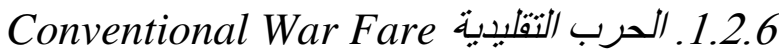

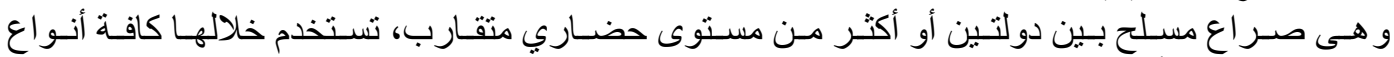

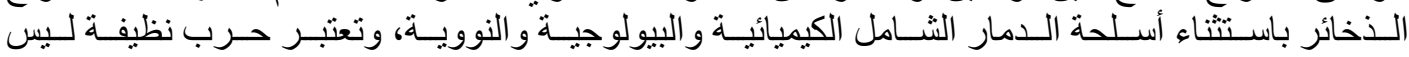
الهدف منها تدمير الدولة إنما التفوق العسكري فقط.

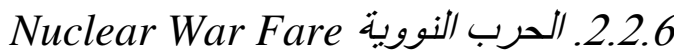

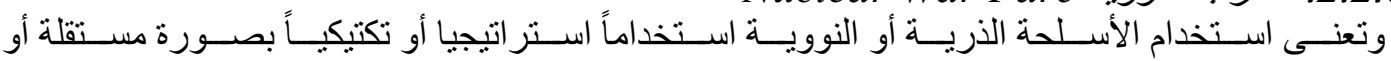
بالتنسيق مع الأسلحة التقليدية الأخرى.

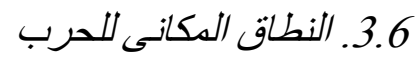
تنقسم الحروب حسب النطاق المكاني التى تنشب به إلى النى:

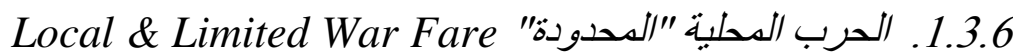

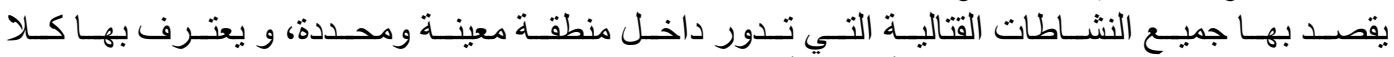
الجانبين وتستخدم في هذه الحرب جميع أنواع الأسلحة.

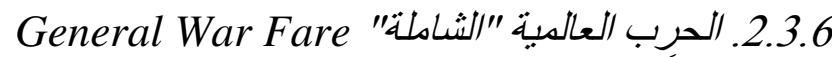

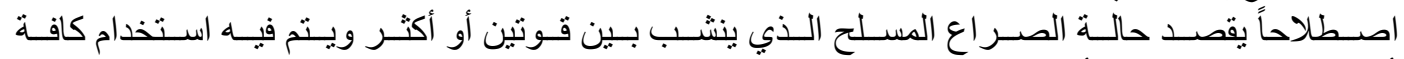
الأسلحة دون تمييز بين الأهداف المدنية والعسكرية.

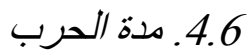

تتنوع الحروب حسب المدة الزمنية التى تستغرقها، ما بين:

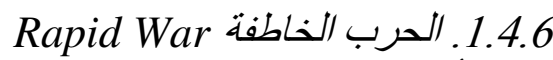

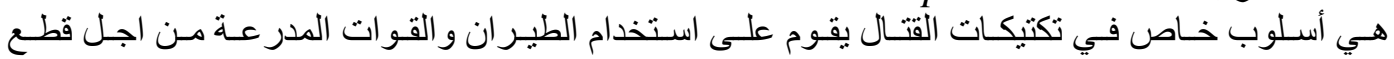

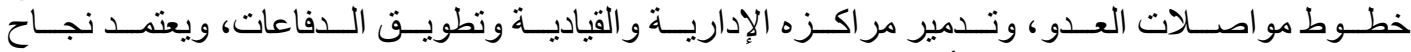

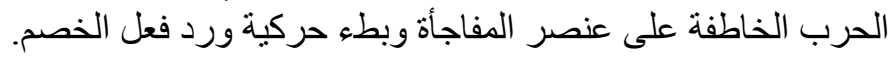

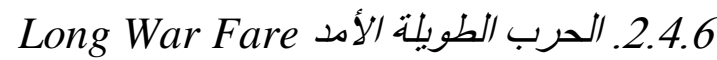

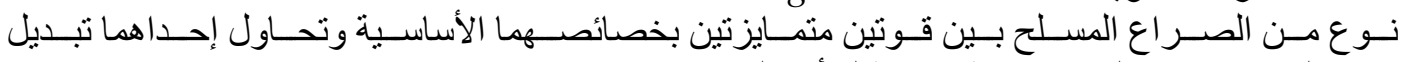

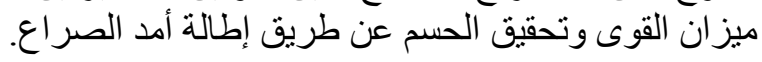

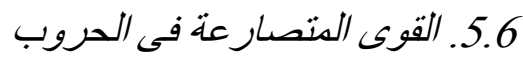

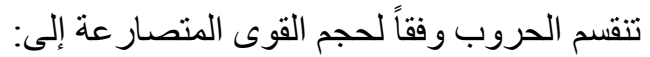

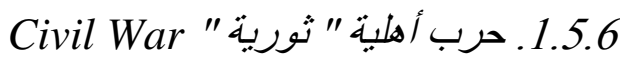

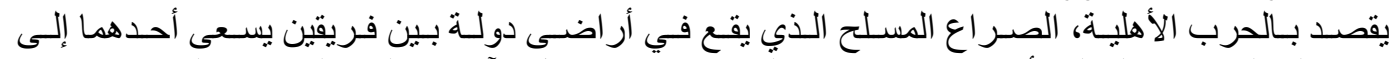

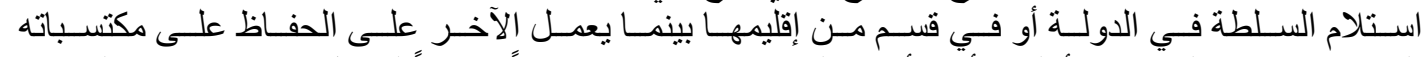

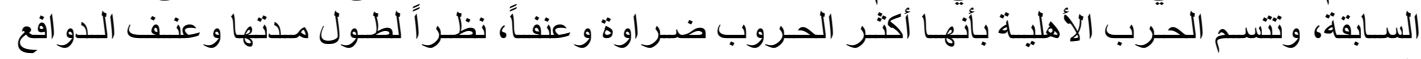
الكامنة ور ائها.

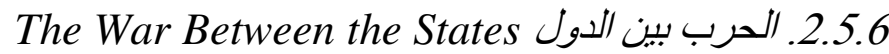

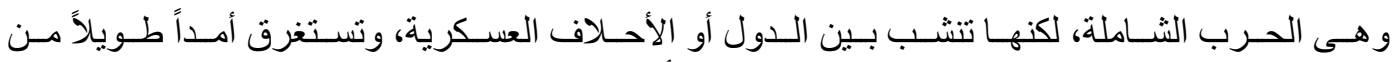

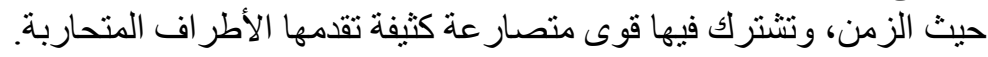

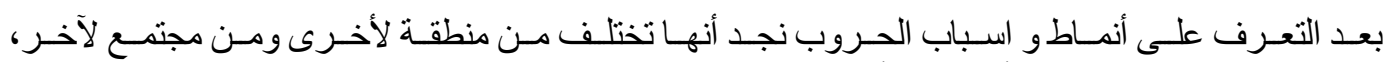

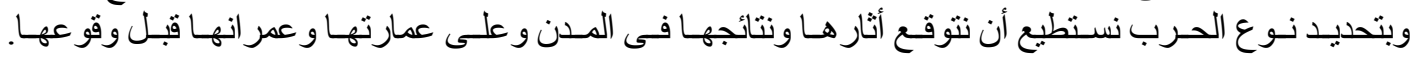


دراسة تحليلية لأثار الحروب على عمارة وعمران الددن العربية

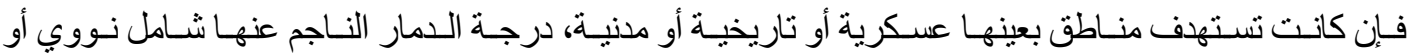
خفيف تقليدي. وبالتالي محاولة اتخاذ الإجر اءات الوقائية لحماية هذه المنشآت قدر الإمكان.

ويبين شكل (1) تصنيف الحروب و أنواعها:

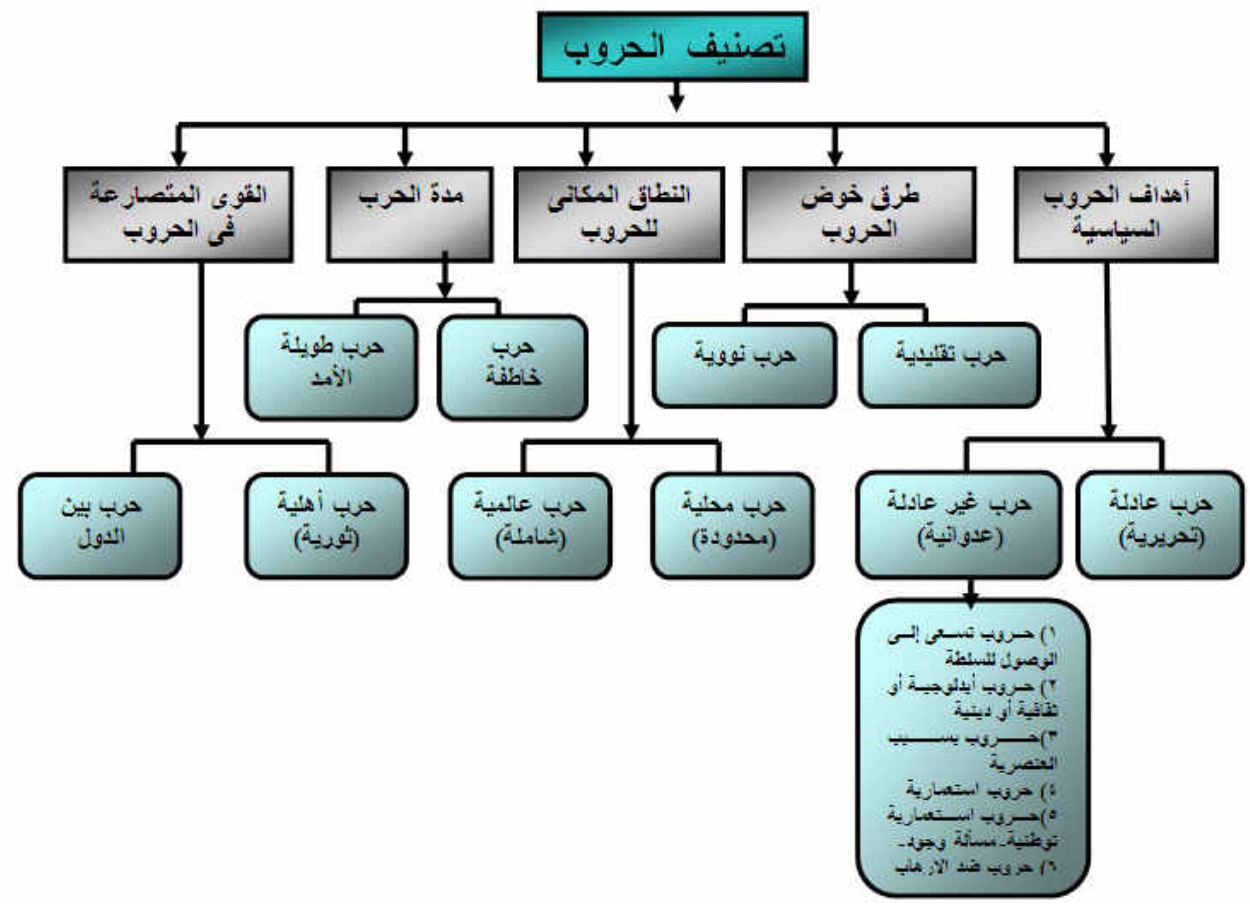

شكل (1): تصنيف الحروب و أنو اعها.3

7. آثار الحروب على عمارة وعمران المدن

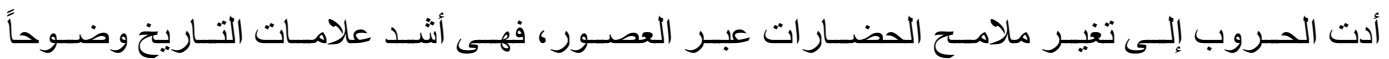

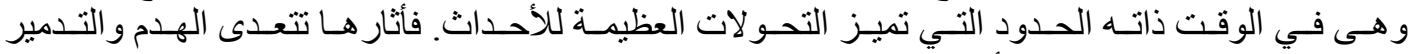

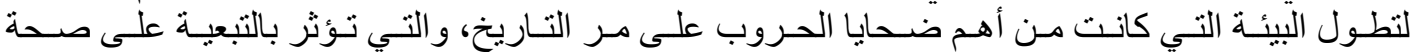

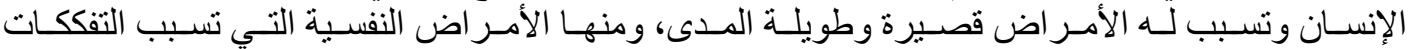

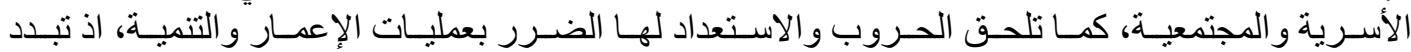

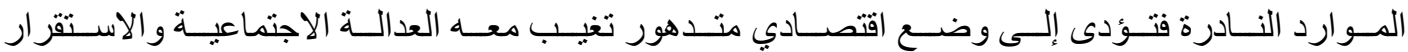

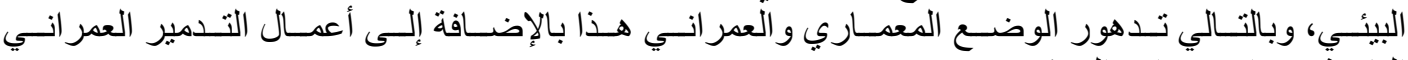
الناتجة عن الاستهداف العسكري.

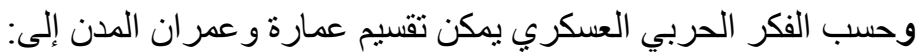

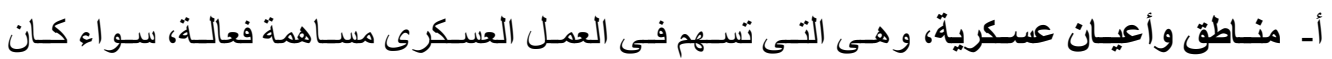

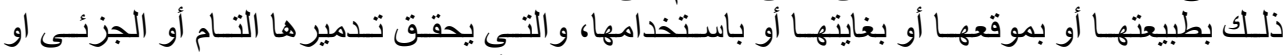

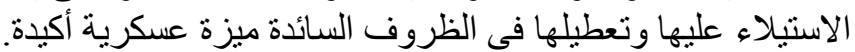

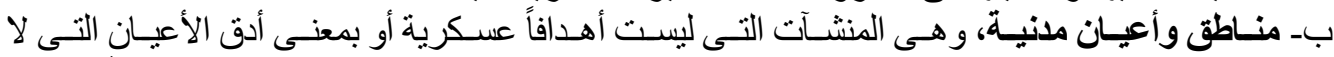

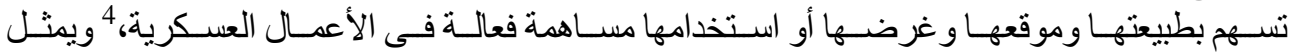

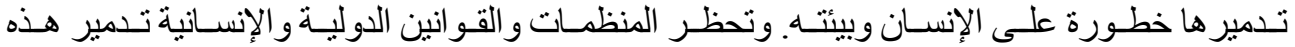


داليا حسن محمد تمام و آخرون

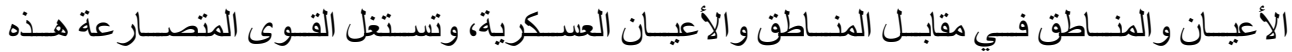

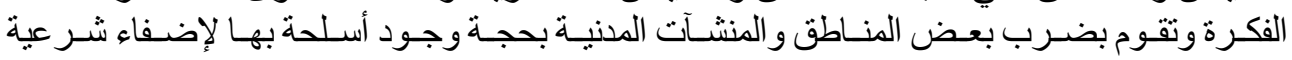
انتهالك حقوق الإنسان وتندمير التاريخ الإنساني للجماعات التهات.

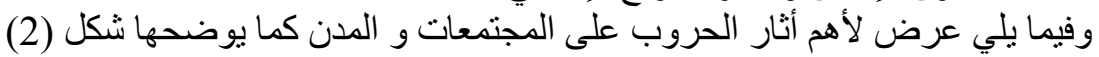

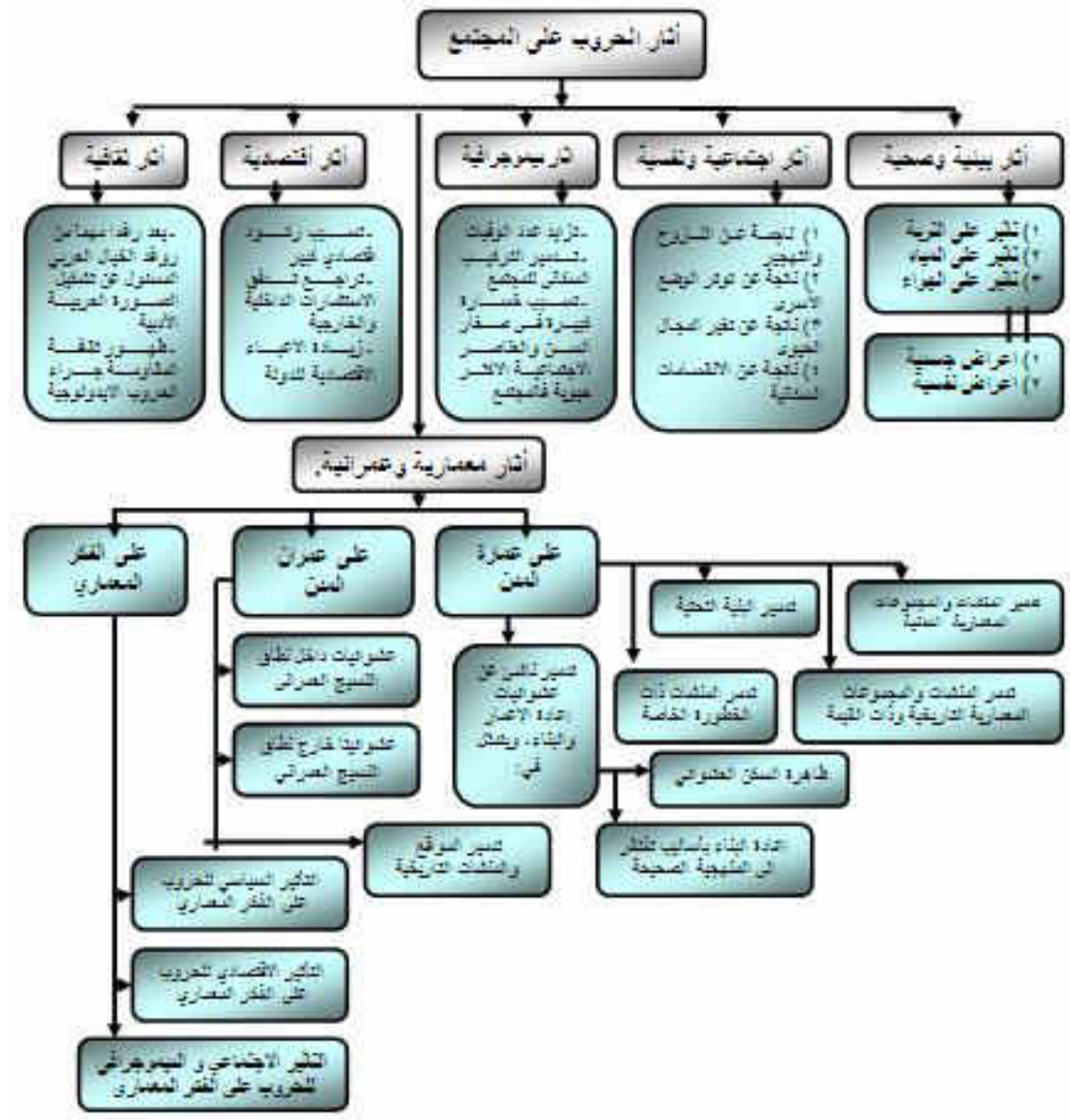

$$
\text { شكل (1): تصنيف الحروب و أنو اعها. } 5
$$

1.7 أثار الحروب على عمارة المدن تتنوع أثنار الحروب على المناطق و المنشآت الحديث منها والتاريخى، و و صور دمار ها كالتالى: تألى

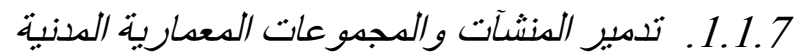

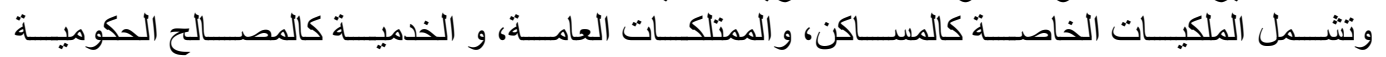

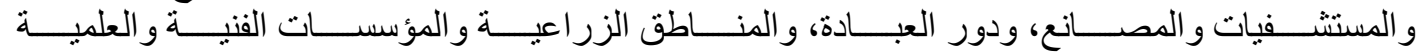

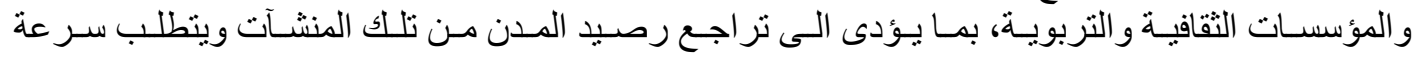
إعادة الإعمار. 2.1.7. تدمبر المنشآت والمجهوعات المعهارية التاربخية وذات القبية

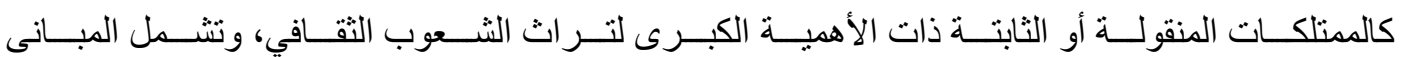

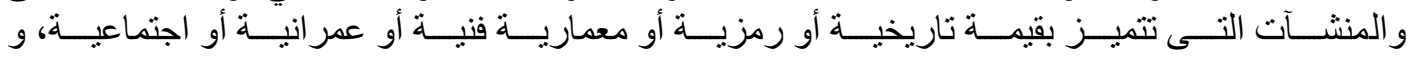




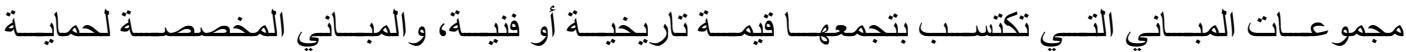

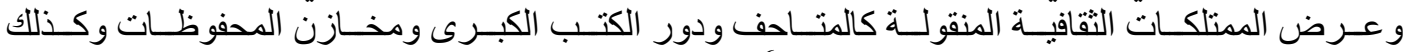
المخابئ المعدة لوقاية الممنلكات الثقافية المنقولة 6

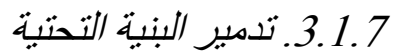

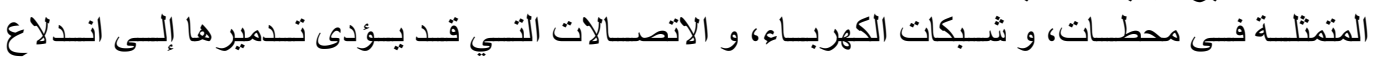

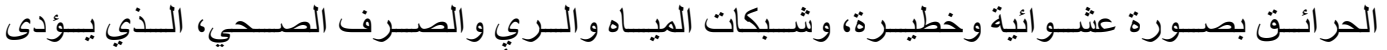

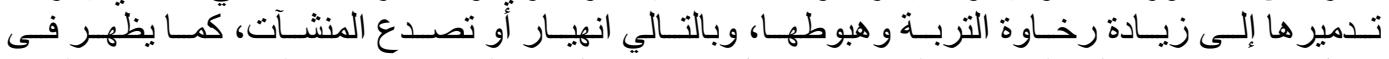

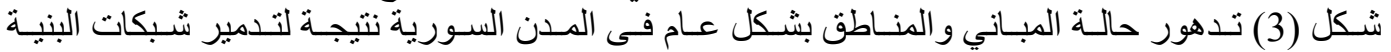
التحتية بها.

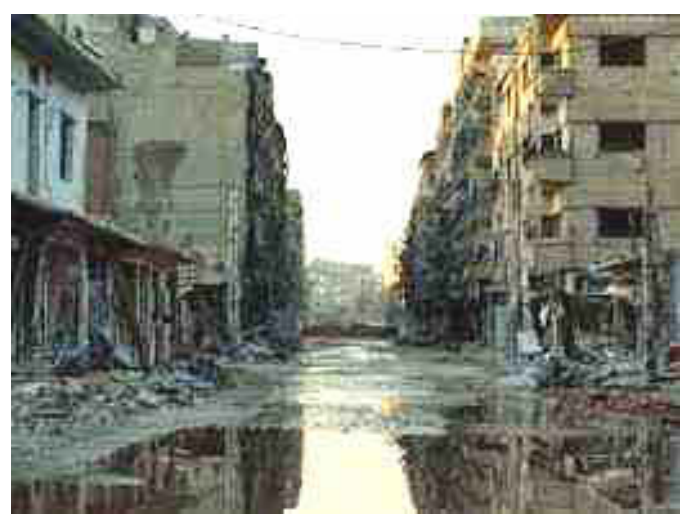

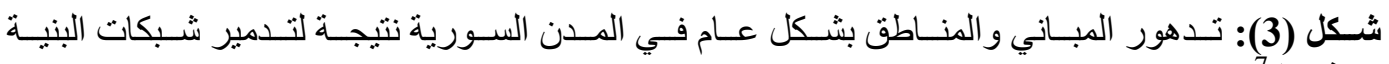
التحتية بها.

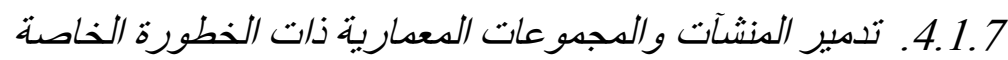

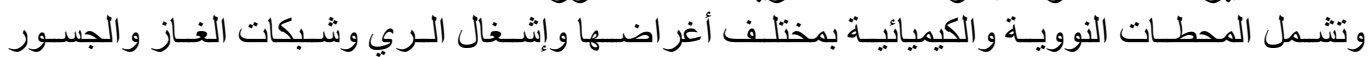

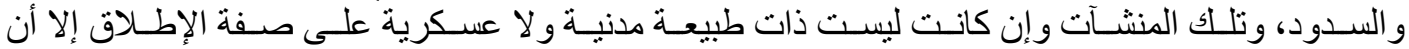

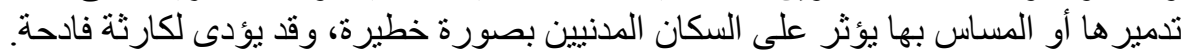

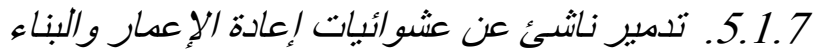

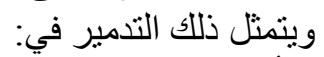

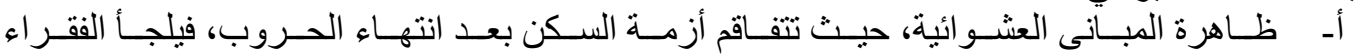

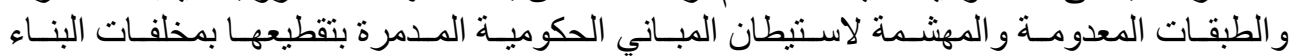
و اتخاذها مأوى لهمه.

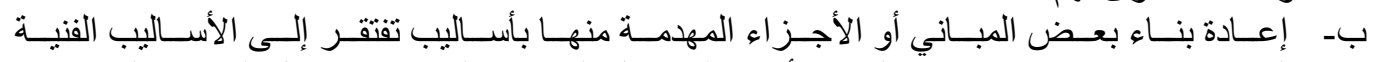

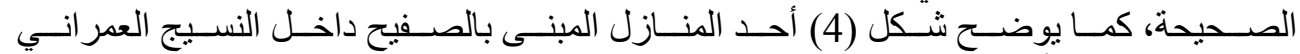
لمنطقة الفارسية بالأغوار فى فلسطين. 


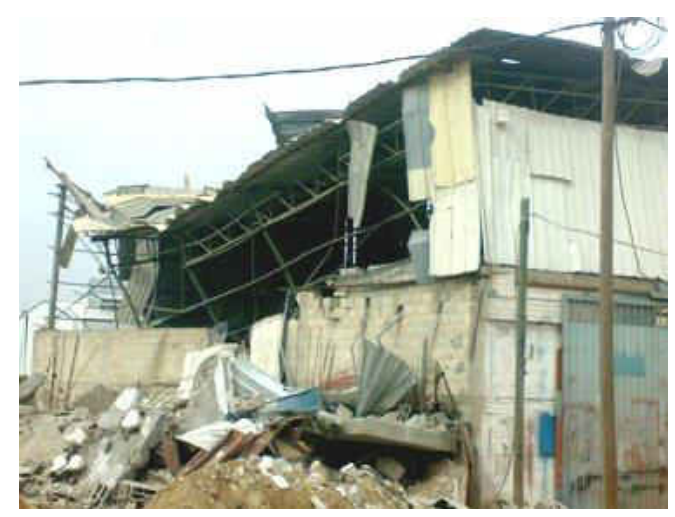

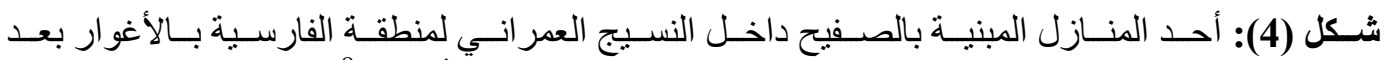

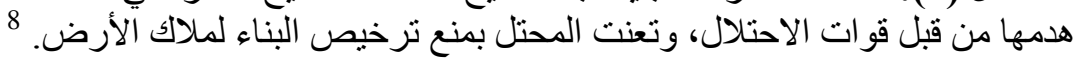

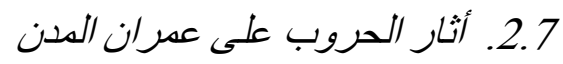

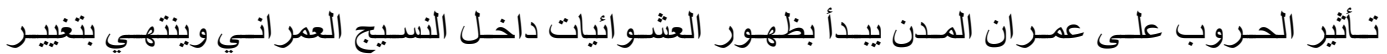

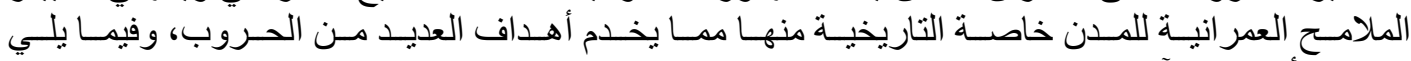

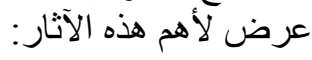

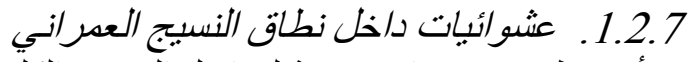

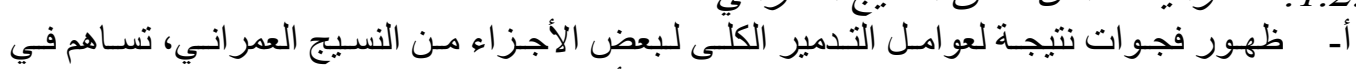

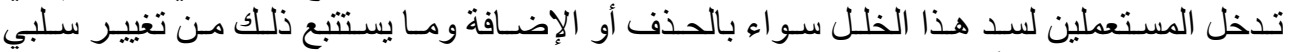
لخريطة استعمالات الأر اضين إندي.

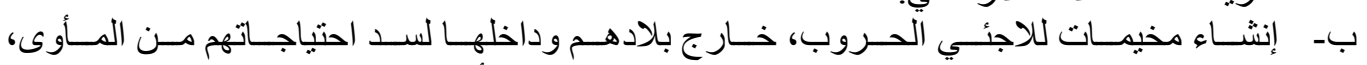

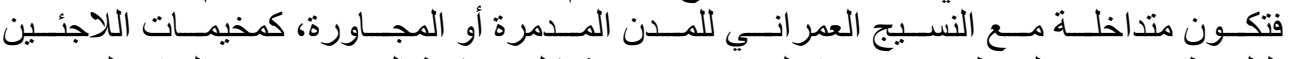

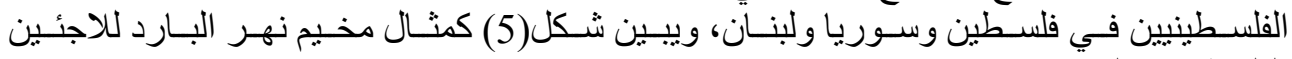
الفلسطينيين بلبنان.

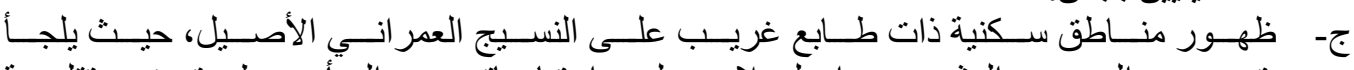

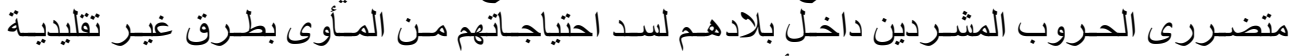

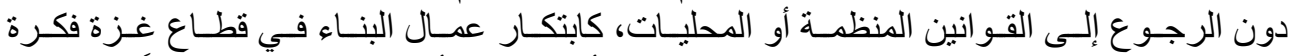

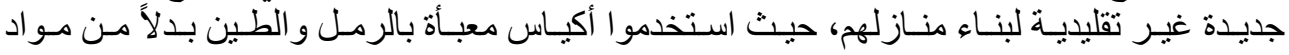

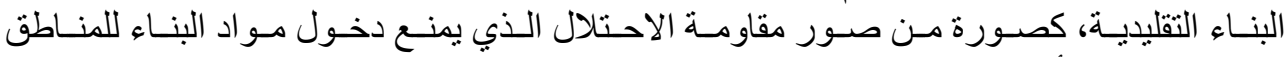

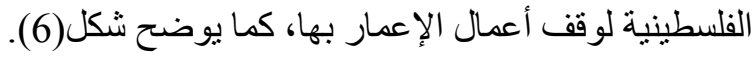




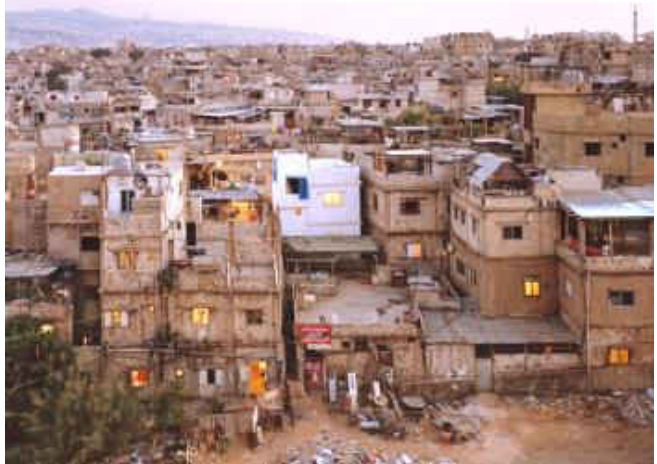

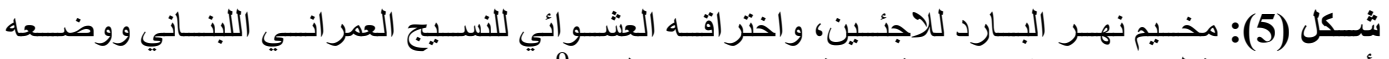
المأساوي، نتيجة لعدم وجود شبكات بنية تحتية جيدة تخدم قاطنيه.

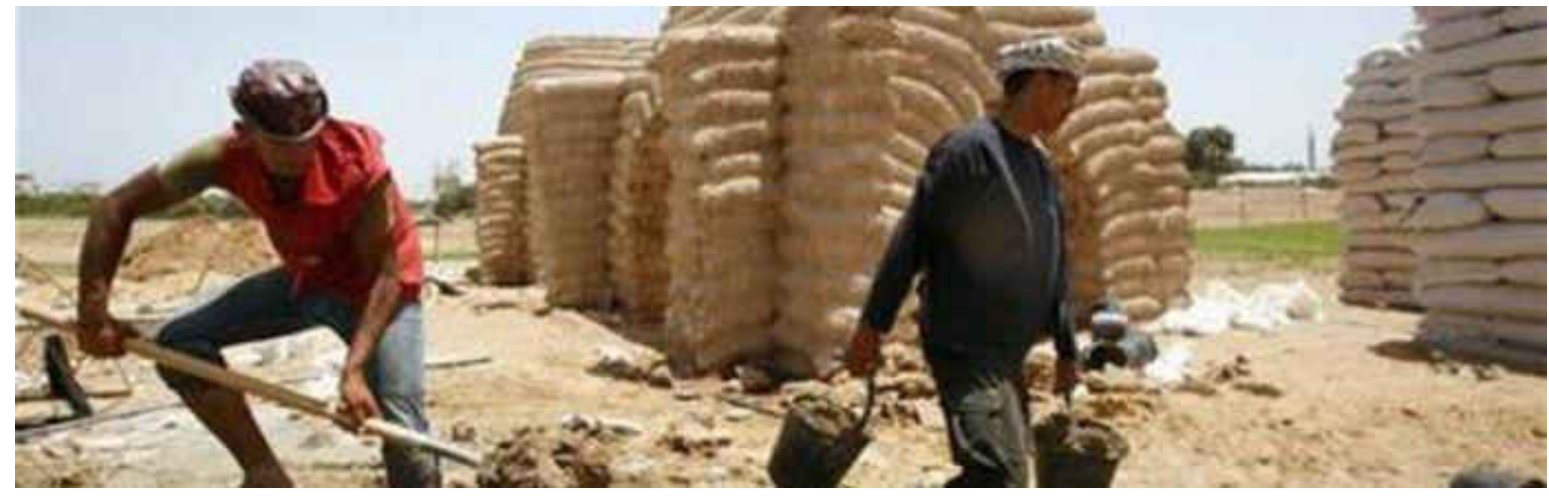

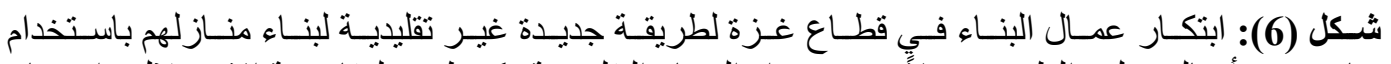

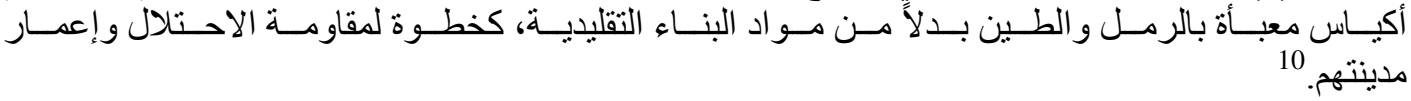

$$
\text { 2.2.7. عشوائبات خارج نطاق النسبج العدرانسي }
$$

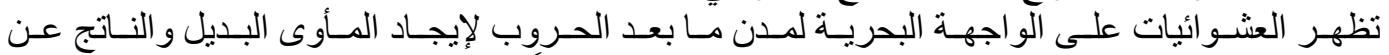

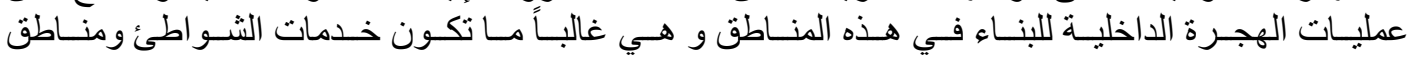

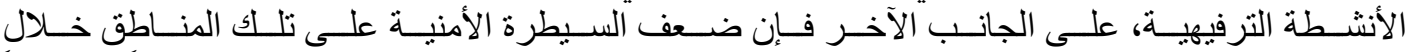

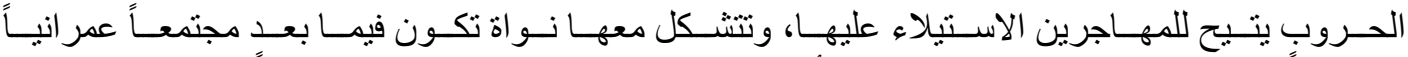

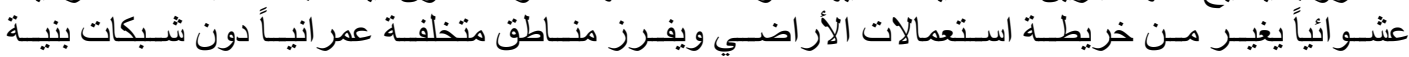

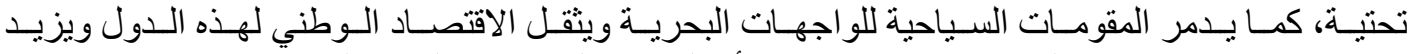

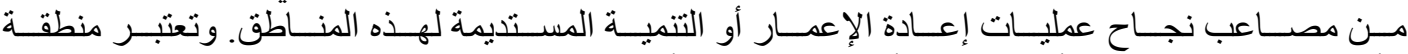

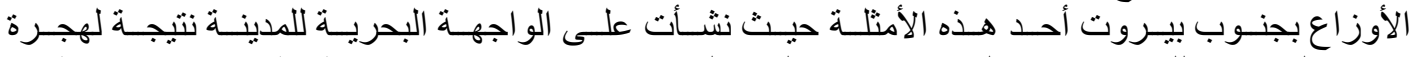
سـكان الجنـوب اللبنـاني وقـت الغـزو الإســر ائيلي بـالجنوب عـام 1982، دون تخطـيط مسـبق، كمـا يظهـر في شكل (7).

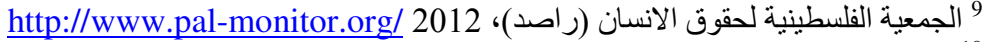
10 "القسعـ الصمود.. البقاء.. التنمية"، منظمة التحرير الفلسطينية، دائرة شؤون المفوضات، فبراير 2012، صـ18 http://www.nad-plo.org/ 


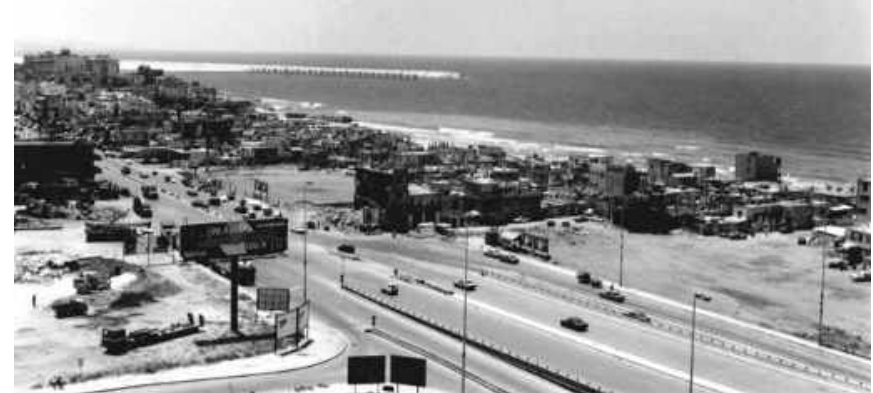

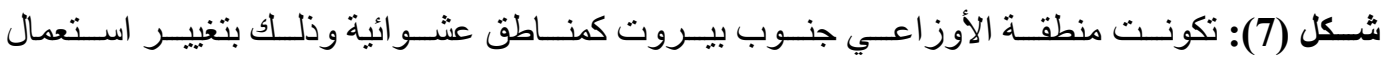

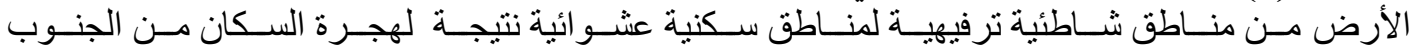

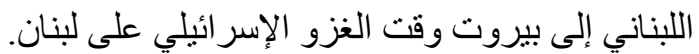

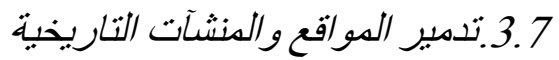

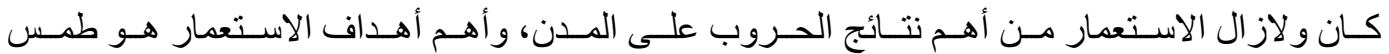

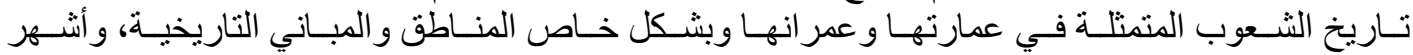

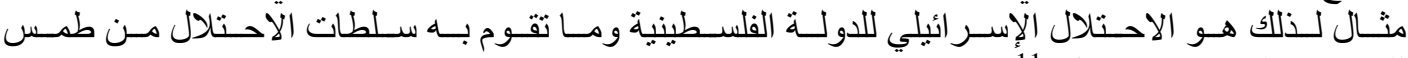

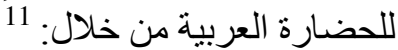

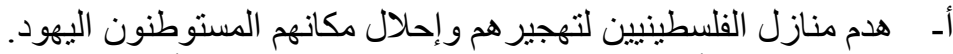
ب- تطبيق قانون "أملاك الغائبين" لسهولة الاستيلاء على والحئ الأر اضي الفلسطينية.

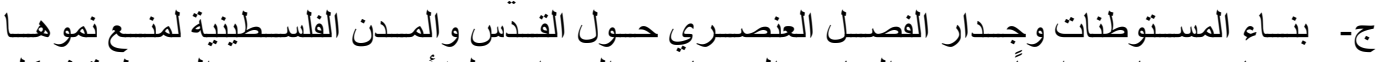

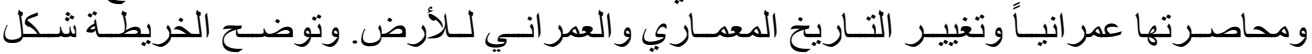

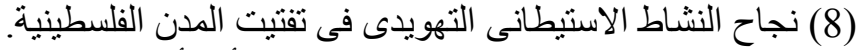

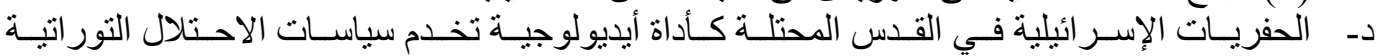

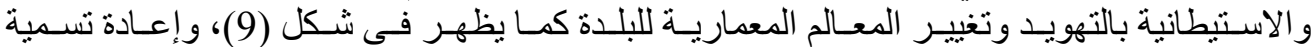
المو اقع و الثوار التو و الأر اضي والتو الوديان و الجبال عبر إعطاءها مسميات عبرية وتور اتية. 


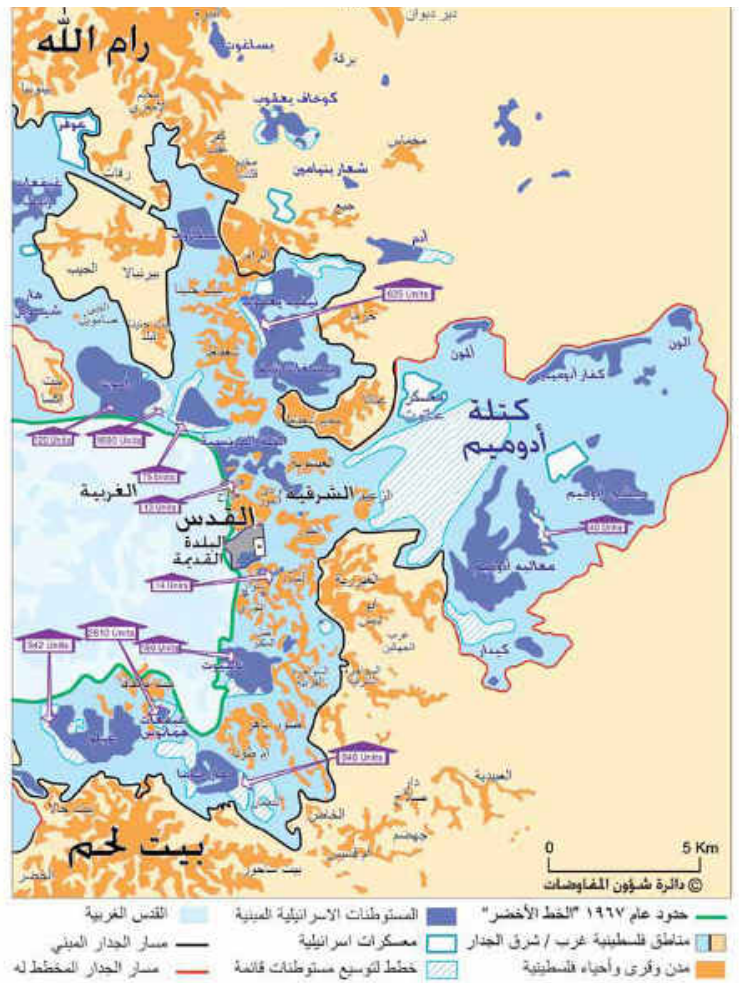

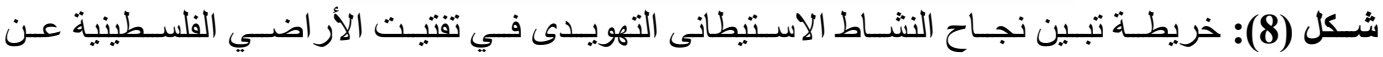

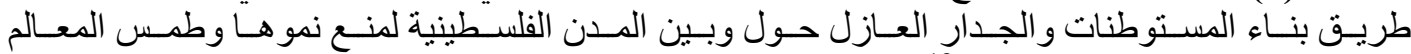
العمر انية للدولة الفلسطينية العربية. 12

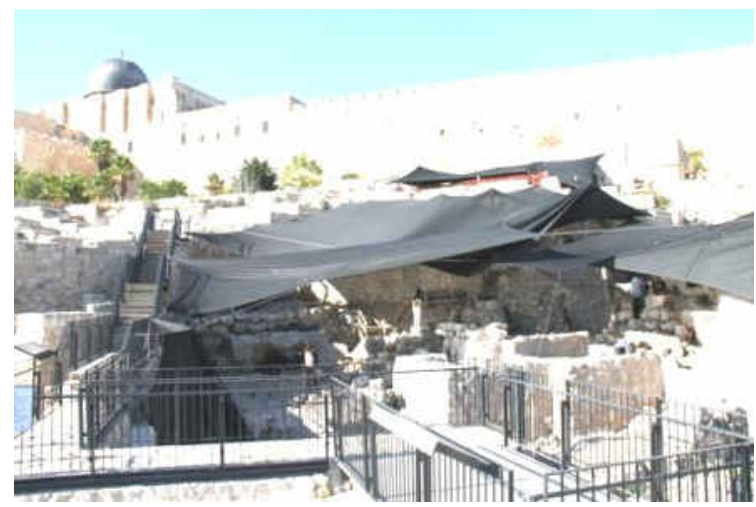

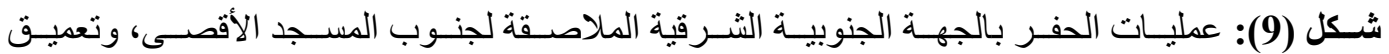

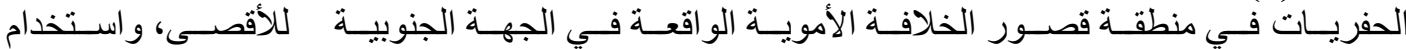

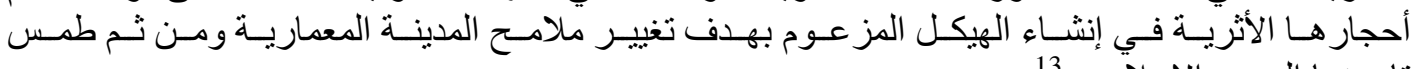
تاريخها العربي الإسلامي. 13

12 "القس- الصمود.. البقاء.. التتمية"، منظمة التحرير الفلسطينية، دائرة شؤون المفوضات، فبر اير 2012، صـ13 http://www.nad-plo.org/ http://www.iaqsa.com/ 13 مؤسسة الأقصى للوقف و التراث، سبتمر 2012 


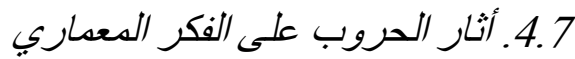

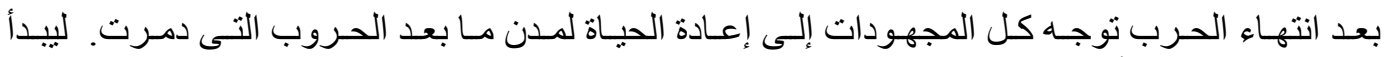

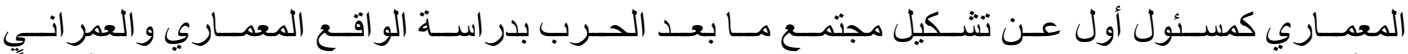

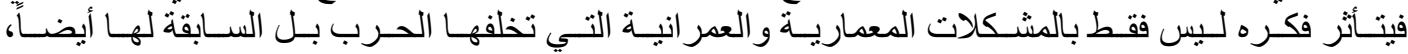

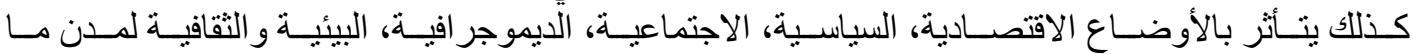
بعد الحروب و التي بمكن إدر اجها فيما يلي:

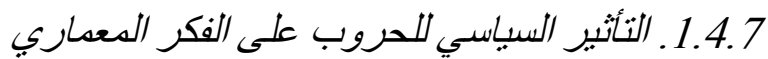

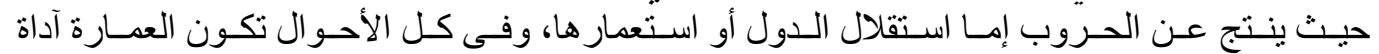

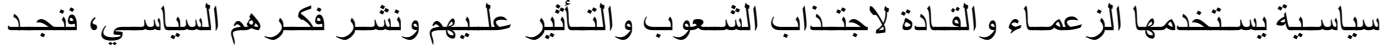

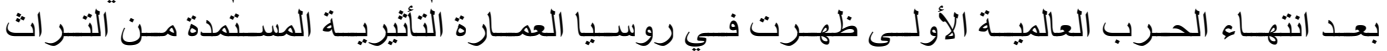

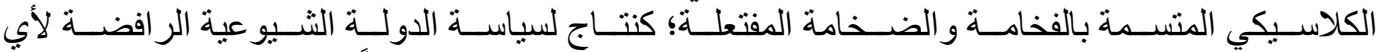

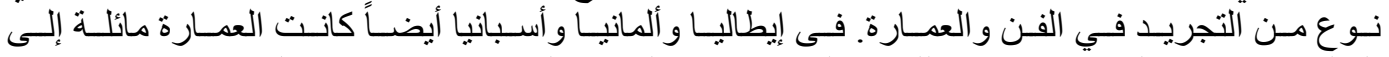

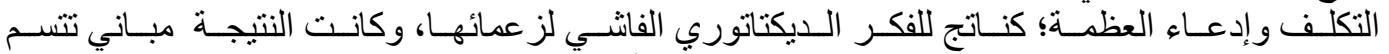

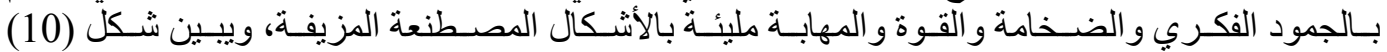

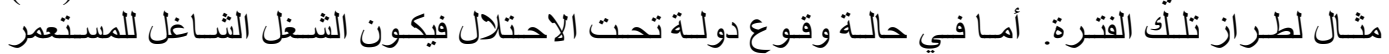

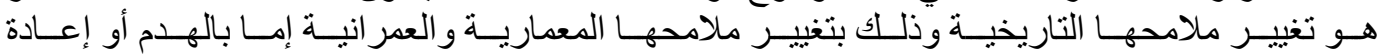

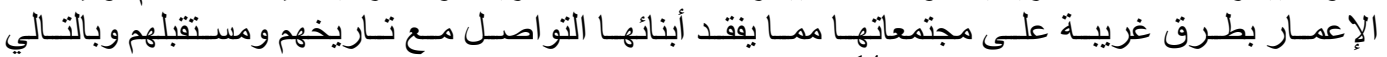
محو التاريخ الإنساني المميز للجماعة. 14
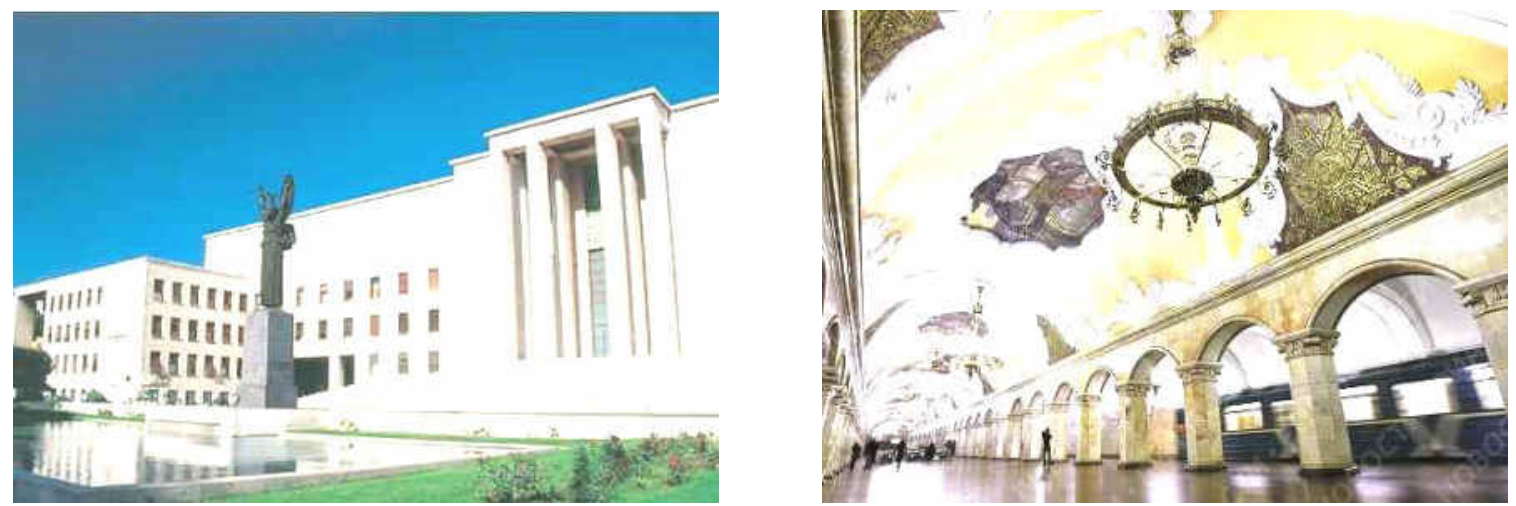

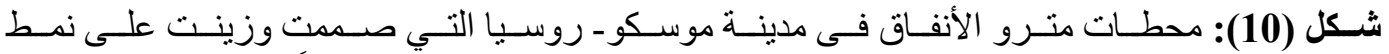

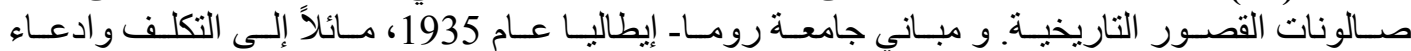

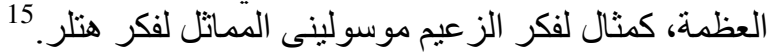

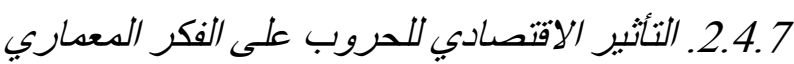

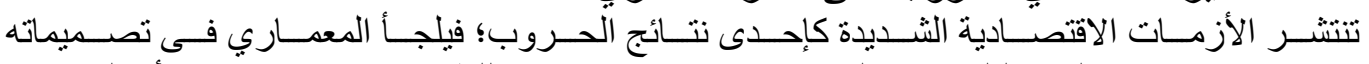

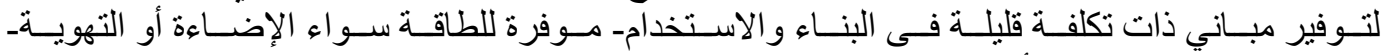

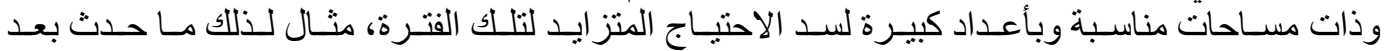

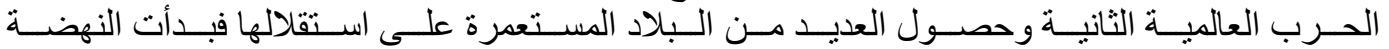

14 صلاح زيتون(أ.د)، "عمارة القرن العشرين- دراسة تحليلية للمهندس المعمارى "، قسم الهندسة المعمارية، كلية الهندسة ،جامعة

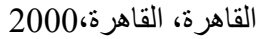
15 صدلاح زيتون(أ.د)، "عمارة القرن العشرين- دراسة تحليلية للمهندس المعمارى "، قسم الهندسة المعمارية، كلية الهندسة ،جامعة 


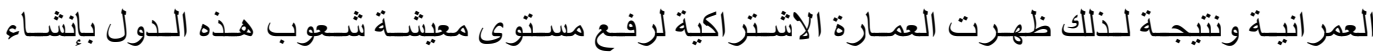

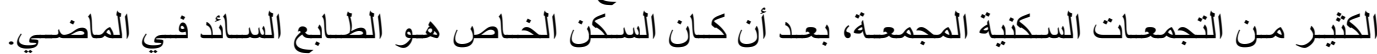

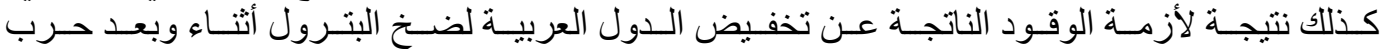

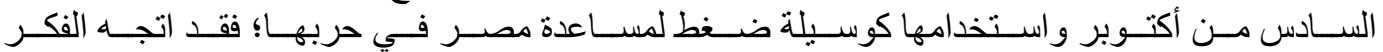

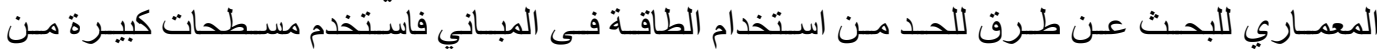

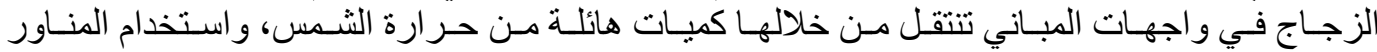

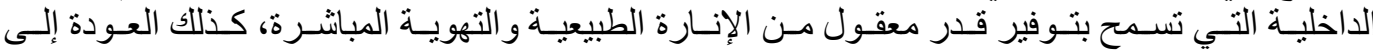

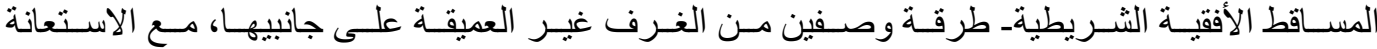

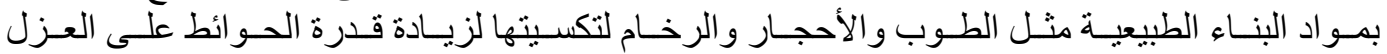

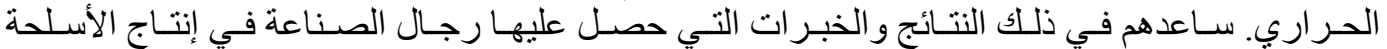

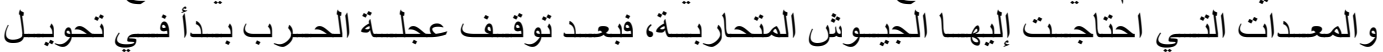

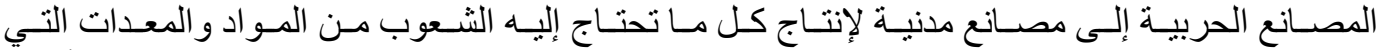

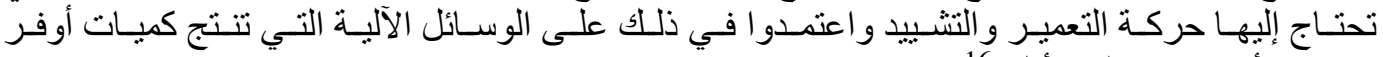
في وقت أسرع وبتكاليف أقل. 16

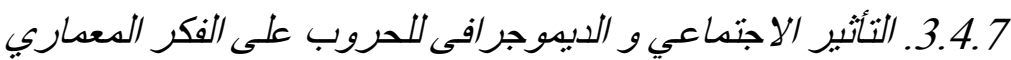

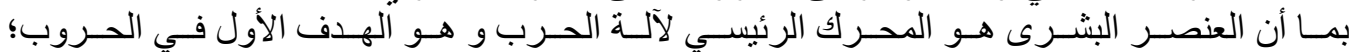

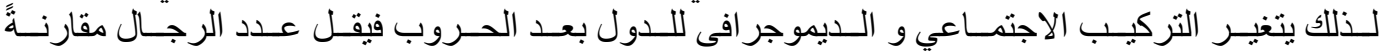

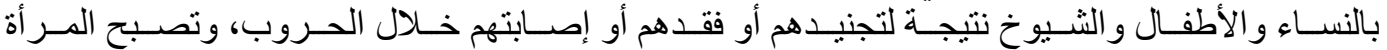

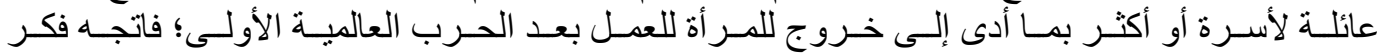

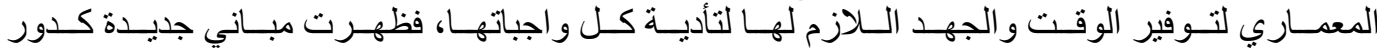

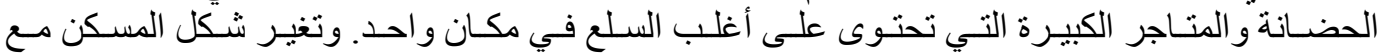

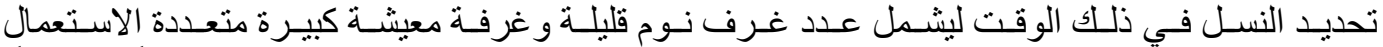

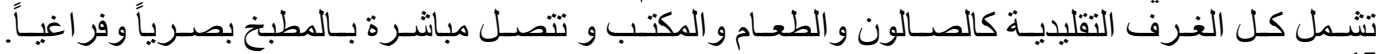

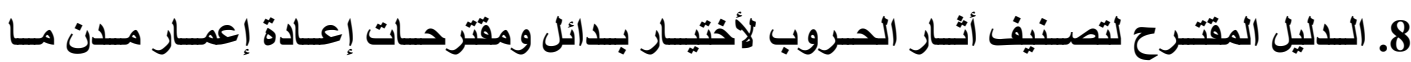
بعد الحروب

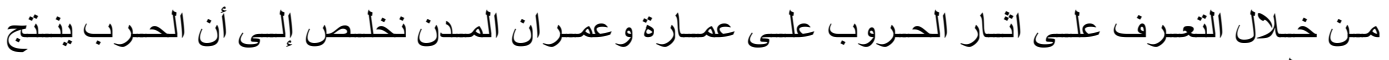
عنها ما يلى: من خدر:

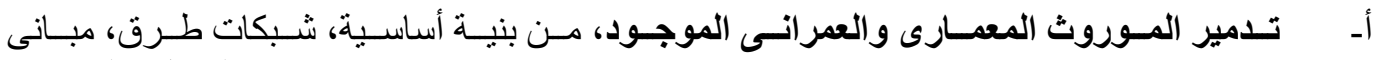

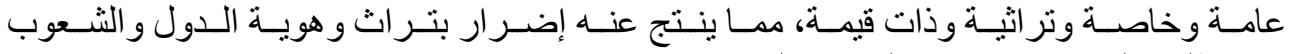

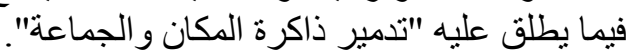

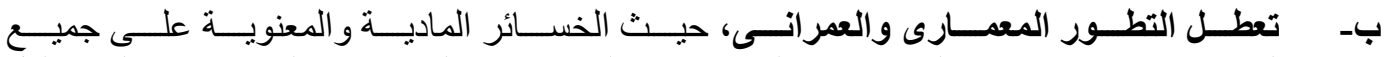

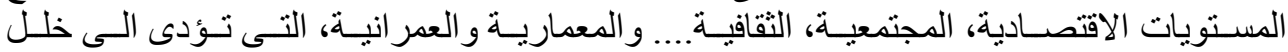

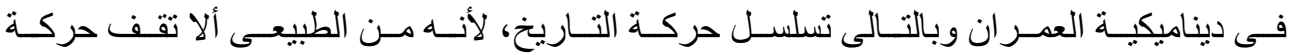
العمر ان بل تستمر باستمر ار الحياة.

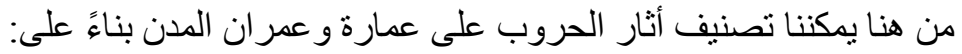

16 صلاح زيتون(أ.د)، "عمارة القرن العشرين- دراسة تحليلية للمهندس المعمارى "، قسم الهندسة المعمارية، كلية الهندسة ،جامعة

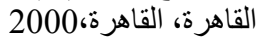
17 صلاح زيتون(أ.د)، "عمارة القرن العشرين- در اسة تحليلية للمهندس المعمارى "، قسم الهندسة المعمارية، كلية الهندسة ،جامعة

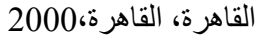




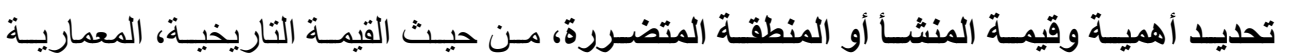

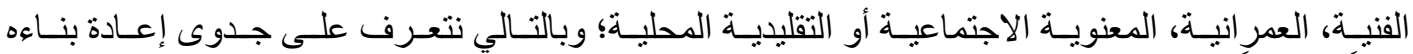

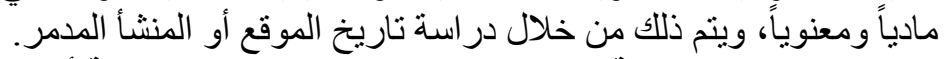

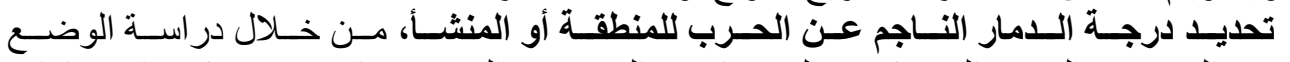

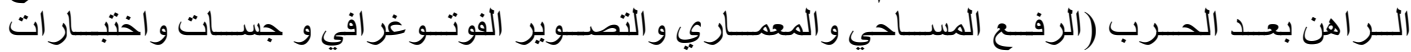

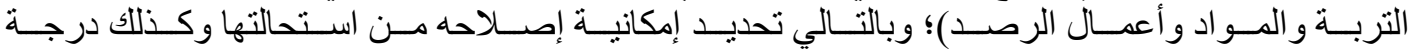

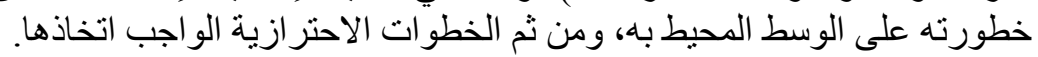

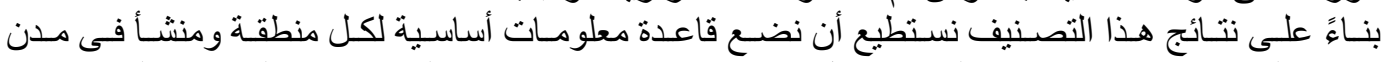

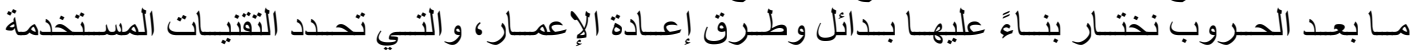

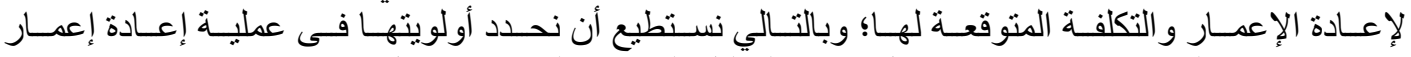

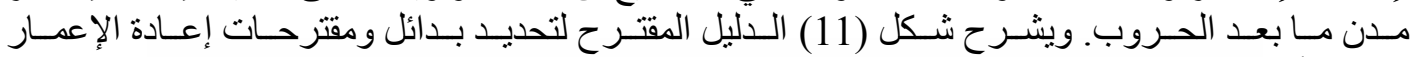

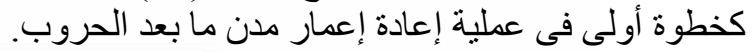

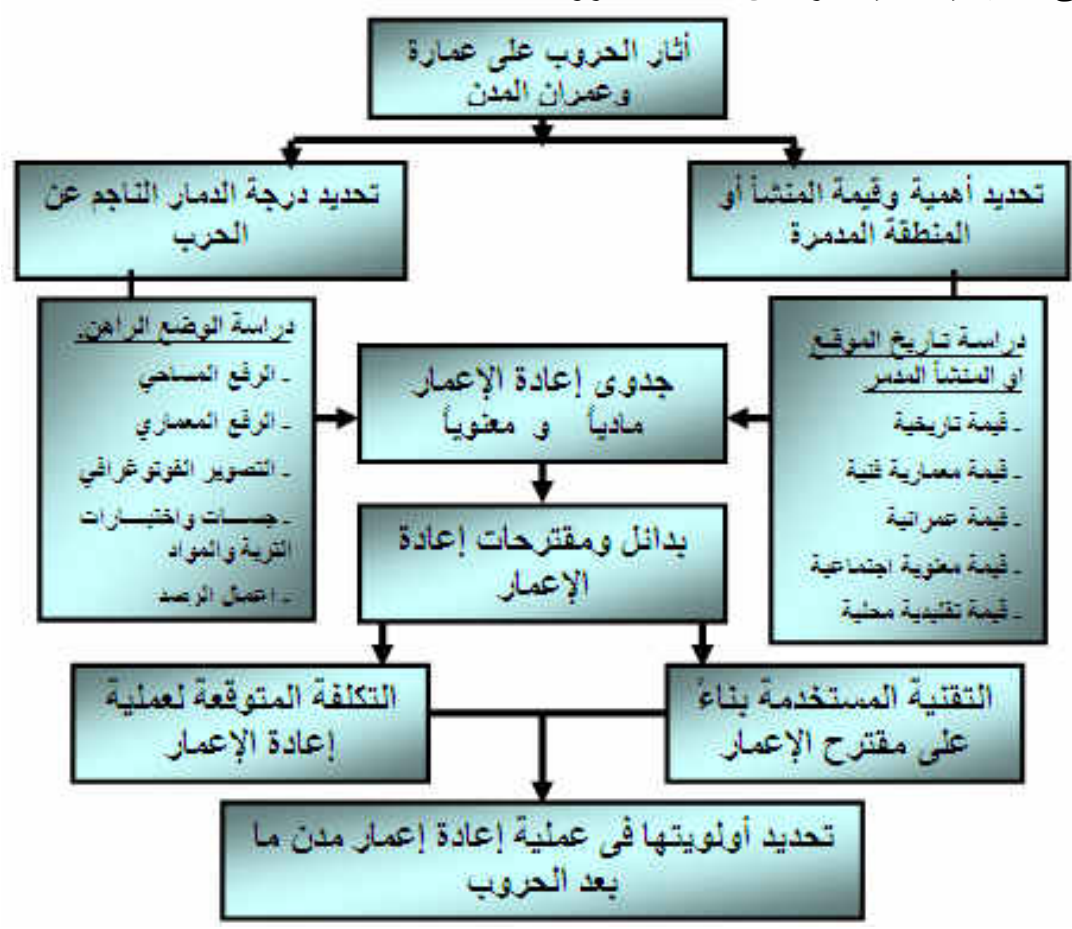

شـكل (11): الـدليل المقتـرح لتصـنيف أثنار الحـروب لأختيـار بـدائل ومقترحسات إعـادة إعمــار مـدن مـا بعد الحروب.

9. النتائج والتوصيات

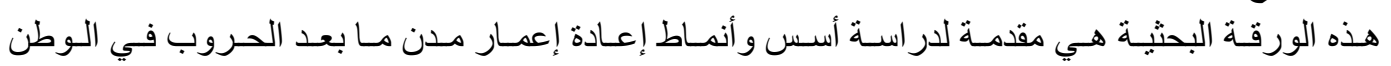
العربي، وقد تم التوصبل فيها إلى النتائج التالية:

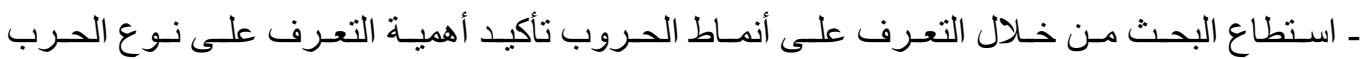

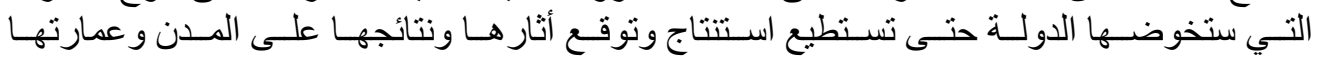


و عمر انهـا قبـل وقو عهــا؛ وبالتــالي العمـل علـى اتخــاذ الإجـر اءات الإسـتعدادية و الوقائيــة لحمايـة ممتلكاتها المادية و المعنوية.

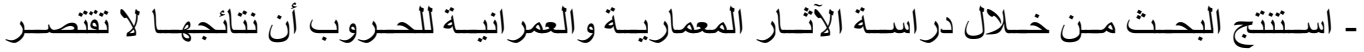

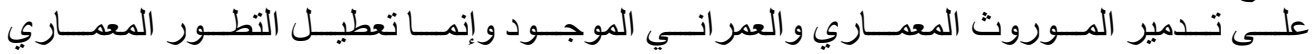

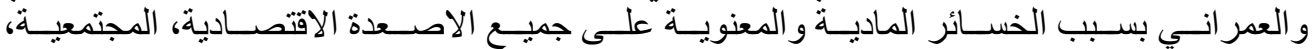

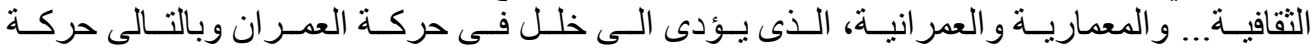
التاريخ. 10. 10 أتوصيات

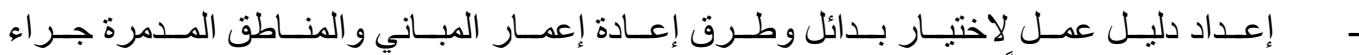

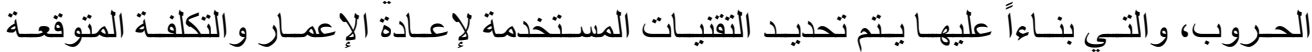

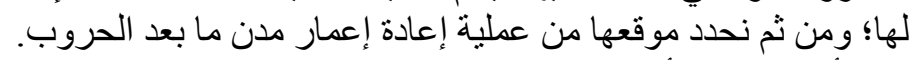

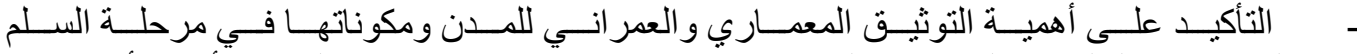

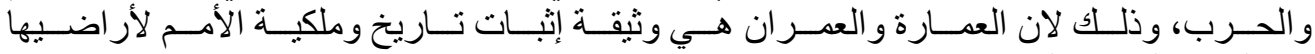
و ومتلكاتها العامة و ولخدة الخاصة.

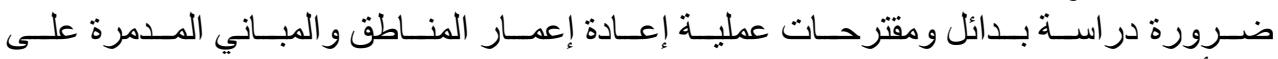
مختلف أنو اعها ودرجات دردة دمار هات

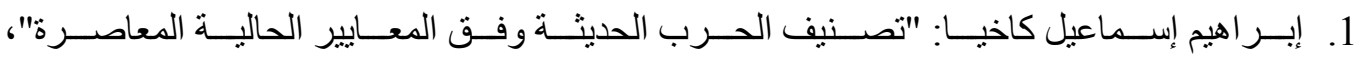
دمشق،2004م 2. أشرف محمد لاشين، "جرائم الاعتداء على الأعيان المدنية"، مركز الإعلام الأمني

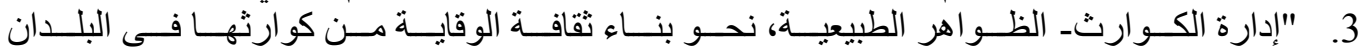

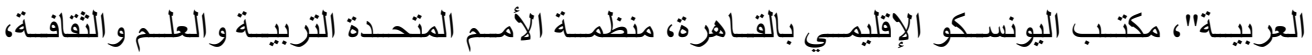
2009

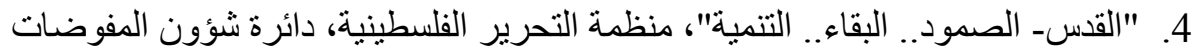

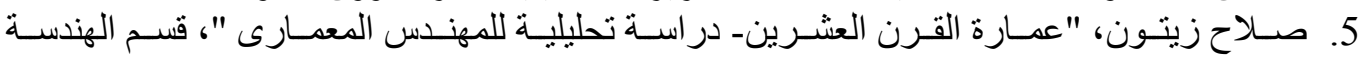

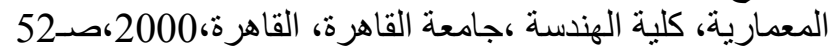

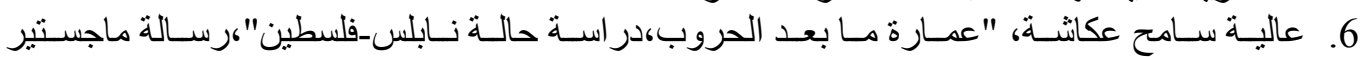

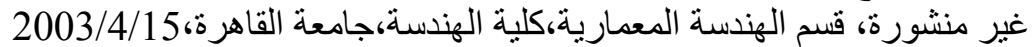

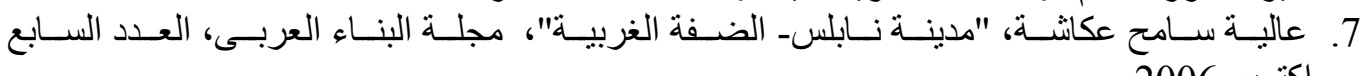
اكتوبر 2006 8. محمد حافظ غانم، "مباديء القانون الدولي العام"، دار النهضة العربية، القاهرة، 1972م المواقع الالكترونية

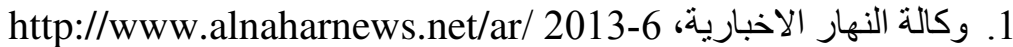

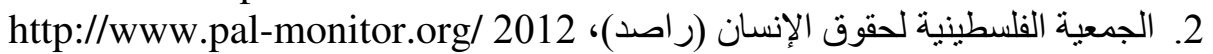

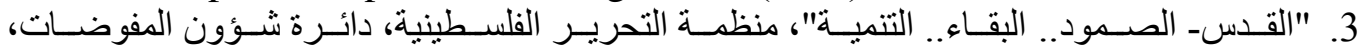
http://www.nad-plo.org/ فبر اير 2012

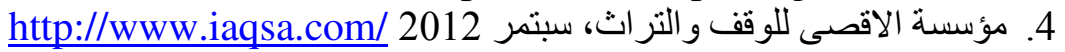


داليا حسن محمد تمام و آخرون

\section{AN ANALYTICAL STUDY AT WARS EFFECTS ON ARCHITECTURE AND URBANIZATION OF ARABIC CITIES}

\section{ABSTRACT}

Wars and armed conflicts became a daily reality for many countries in the Arab world. In spite of this, the prevention strategy of disasters - especially wars- disabled- , Therefore, the effects of these conflicts are worsening day after day at all levels, Environmental, social, cultural, architectural and urban, War destroyed many heritage valued buildings, and plundering public and private property, it's a historical and humanitarian disaster. The architecture of today is the history of future.

Therefore, this research aims to study the effects of wars upon architecture and inhabitances of Arab cities, By studying patterns of wars which theses countries may be exposed, and analyze the most important effects of wars upon architecture and inhabitances regarding some Arab cities. The research suggests a practical guide for the classification of these effects, and based on these results we can develop a data base for each key area and a facility in the after-war cities we choose - upon it- alternatives and methods of reconstruction which determines the applicable techniques and the expected Thus we can determine its priorities in the after war cites reconstruction process.

This research has proved that the effects of war on the cities is not just a mere demolition and destruction, but lead to an imbalance in the movement of inhabitances thus the movement of history. Research has recommended the importance of architectural documentation of the cities and their components as well as the need to examine alternatives and proposals for the reconstruction process. 